Article (non-refereed) - postprint

Harmens, H.; Schroder, W.; Zechmeister, H.G.; Steinnes, E.; Frontasyeva, M. 2015. Comments on J.A. Fernandez, M.T. Boquete, A. Carballeira, J.R. Aboal (2015). A critical review of protocols for moss biomonitoring of atmospheric deposition: sampling and sample preparation. Science of the Total Environment 517: 132-150.

(C) 2015 Elsevier B.V.

This manuscript version is made available under the CC-BY-NC-ND 4.0 license http://creativecommons.org/licenses/by-nc-nd/4.0/

(c) EY-NG-ND

This version available http://nora.nerc.ac.uk/512168/

NERC has developed NORA to enable users to access research outputs wholly or partially funded by NERC. Copyright and other rights for material on this site are retained by the rights owners. Users should read the terms and conditions of use of this material at http://nora.nerc.ac.uk/policies.html\#access

NOTICE: this is the author's version of a work that was accepted for publication in Science of the Total Environment. Changes resulting from the publishing process, such as peer review, editing, corrections, structural formatting, and other quality control mechanisms may not be reflected in this document. Changes may have been made to this work since it was submitted for publication. A definitive version was subsequently published in Science of the Total Environment (2015), 538. 1024-1026.

10.1016/j.scitotenv.2015.07.070

www.elsevier.com/

Contact CEH NORA team at noraceh@ceh.ac.uk

The NERC and CEH trademarks and logos ('the Trademarks') are registered trademarks of NERC in the UK and other countries, and may not be used without the prior written consent of the Trademark owner. 


\section{Comments on J.A. Fernandez, M.T. Boquete, A. Carballeira, J.R. Aboal (2015). A critical review of protocols for moss biomonitoring of atmospheric deposition: Sampling and sample preparation. Science of the Total Environment 517: 132-150.}

We are impressed by this extensive review of the use of mosses as biomonitors of atmospheric pollution, primarily heavy metals. The authors did a very good job collating all this data. We applaud their efforts trying to improve the ICP Vegetation moss monitoring manual. However, we would like to take the opportunity to comment on the paper, indicating some flaws and errors, some of which were expressed by reviewers during the review process but not taken on board in the final version of the paper:

1. An important part of the paper is to assess the application of the ICP Vegetation moss monitoring manual in the studies included in the paper. However, many of these studies have different aims from the European moss monitoring survey and therefore did not necessarily aim or even indicate to follow the ICP Vegetation protocol. The aim of the ICP Vegetation moss survey is to assess the sufficiency and effectiveness of the air pollution abatement policies of the LRTAP Convention and its Protocols, particularly the Protocol on Heavy Metals. The focus of the Convention is long-range transboundary air pollution. Various studies quoted in the paper had the aim to study small scale air pollution near local pollution sources and therefore had a different aim from the European moss survey. The aim of the ICP Vegetation protocol is to be as widely applicable as possible across Europe, which might not always be the best protocol for more local or national scale application. 
2. Harmonization of methods is needed to ensure that different measurement values reflect spatial and/or temporal differences in observed objects but not in methods applied. Harmonization should be based on scientifically sound criteria such as transparency, objectivity, correctness and reliability/precision of measurements/ observations, validity of measured variables. These criteria not only hold true for empirical research but also for literature research. Here, the manuscripts reviewed are objects of research. The review paper does not meet the quality criteria of an objective analysis. Some of the papers cited were clearly misunderstood. Besides this, the aim of this review cannot be reached by the approach the authors took. The question whether there is a need for harmonization has to be answered not only based on literature research but should additionally be based on a comprehensive statistical analysis of data on heavy metal and nitrogen concentrations in mosses and other metadata collected across Europe (see point 7).

3. Improvements of the moss monitoring manual suggested by the authors are often based on examples from very few studies, sometimes only single studies conducted by the Santiago research group. Although these studies are scientifically sound at the regional scale, this does not result in a more appropriate protocol for the larger scale. Climate, topography, seasonality, land use etc. vary widely across Europe and hence the deposition of metals to mosses too. Therefore, it would be unrealistic to think that methodologies that work at a small, selected number of sites, or methodologies that have only been proven to work in a comparable small area with a very distinct climate (Galicia in Spain in this case), simply could be applied to the whole of Europe. For this reason, the ICP Vegetation protocol does not always give stringent guidelines but has flexibilities build in. The authors have done the same for the improved protocol 
shown in Table 1 of the paper, e.g. sampling site density (1.1), survey frequency (1.3). The scientific quality of the European protocol cannot be fully assessed from its application in very specific local and regional applications within countries.

4. When the moss monitoring was first developed, much information quoted in the paper that could have led to a more 'ideal' protocol was not available yet. However, participants of the European moss survey have met annually since 2000 at the ICP Vegetation Task Force meetings (see http://icpvegetation.ceh.ac.uk) to discuss further development of the survey, the protocol and the results of the five-yearly survey. Although the Santiago group is invited to these meetings as participants of the European moss survey, so far they have not attended any of these meetings to discuss improvements of the protocol. If they had attended these annual meetings, they would have known that decisions on improving the protocol are not only based on scientific papers but also on many national reports produced by the participants of the moss survey. Although we understand that including the material from such reports was beyond the scope of the paper, it is important to know that they exist and contain scientific evidence for some of the issues discussed in the paper. As already mentioned under point 1 , the final decision on making changes to the protocol depends on the applicability across Europe.

5. As a community we realise that the current protocol is far from ideal, however, decisions are also grounded in reality. For example, as referred to by the authors of the paper, ideal improvements based on science are not always feasible due to economic reason (i.e. lack of funding) or spatial limitations, including for example:

- Sampling twice a year and more frequently than every five years; 
- Collecting 30 sub-samples per site;

- Having a minimum distance of twice the height of the trees, e.g. in densely forested countries such as Slovenia (Skudnik et al., 2014, as studied for nitrogen) or in dry areas where mosses are only able to survive near trees (e.g. parts of France). Please note that if the mosses are sampled close to the trees, we ask participants to report on the distance to the nearest trees so we can assess the influence of the distance to the trees on heavy metal concentrations in mosses (see spreadsheet at http://icpvegetation.ceh.ac.uk/manuals/moss_survey.html).

6. One of the main aims of the European moss survey is also to establish temporal trends in heavy metal concentrations in mosses (e.g. Harmens et al., 2010; 2015). Hence, it is important only to make changes to the protocol based on scientific evidence applicable to a wide area of Europe, so temporal trends are not confounded by changes in the protocol over the years. In a previous publication the Santiago group has acknowledged that mosses can be used as biomonitors for at least the heavy metals cadmium and lead (Aboal et al., 2010). Indeed, recent publications have confirmed that modelled atmospheric deposition is the principle component determining cadmium and lead concentrations in mosses (Holy et al., 2009; Schröder et al., 2010). This is true both at the European and national scale (e.g. Germany). Recent publications have also shown that the temporal trends $(1990-2005$ Harmens et al., 2010; 1990 - 2010 - Harmens et al., 2015) of cadmium and lead concentrations in mosses are almost identical to those calculated for modelled deposition with the EMEP (European Monitoring and Evaluation Programme) model. Hence, despite using a less than perfect protocol, moss data provide a very good indication of the temporal trends of the atmospheric deposition in Europe, at least for 
cadmium and lead. It should be noted that at the European scale the comparison between moss data and deposition data can only be made for cadmium, lead and mercury as EMEP focusses on these metal identified as a priority by the LRTAP Convention.

7. The ICP Vegetation group acknowledges that further metadata regarding the moss sampling sites and the conditions of sampling are required to improve our understanding how various factors might affect heavy metal concentration in mosses. Hence, German participants in the moss survey have developed a database for metadata (MossMet) to enable detailed geostatistical analysis of the data according the methodologies described by for example Holy et al. (2009) and Schröder et al. (2010). MossMet was originally developed to enable a comprehensive statistical analysis in Germany of data on heavy metal (and nitrogen) concentrations in mosses AND data on the sampling sites (moss species, canopy drip effect etc.) AND data on their surroundings (land use, atmospheric deposition etc.) AND metadata on boundary conditions of data production (sampling, chemical/physical methods etc.). Although this has been included in the current moss survey protocol, the authors fail to mention it in the paper. In addition, they fail to refer to Holy et al. (2009) and Schröder et al. (2010) and more recent papers of the German group, describing detailed geostatistical analyses of the European moss data. For economic reasons (see point 5), the submission of metadata to MossMet is not mandatory in the ICP Vegetation protocol.

8. As already implied in point 6 and 7 , the authors have ignored some key papers of the European moss survey, where some of the issues described in the current paper have been either discussed or analysed in a statistical, scientific way (last two papers in the 
list below). In addition, those papers provide background information regarding the European moss survey. This is the more surprising because the authors are co-authors on some of those papers. These relevant key papers are:

Harmens, H., Ilyin, I., Mills, G., Aboal, J.R., Alber, R., Blum, O., Coşkun, M., De Temmerman, L., Fernández, J.A., et al. (2012). Country-specific correlations across Europe between modelled atmospheric cadmium and lead deposition and concentrations in mosses. Environmental Pollution 166: 1-9.

Harmens, H., Norris, D.A., Steinnes, E., Kubin, E., Piispanen, J., Alber, R., Aleksiayenak, Y., Blum, O., Coşkun, M., Dam, M., De Temmerman, L., Fernández, J.A., et al. (2010). Mosses as biomonitors of atmospheric heavy metal deposition: spatial and temporal trends in Europe. Environmental Pollution 158: 3144-3156.

Harmens, H., Norris, D.A., Koerber, G.R., Buse, A., Steinnes, E., Rühling, Å. (2008). Temporal trends $(1990$ - 2000) in the concentration of cadmium, lead and mercury in mosses across Europe. Environmental Pollution 151: 368-376.

Harmens, H., Norris, D.A., Koerber, G.R., Buse, A., Steinnes, E., Rühling, Å. (2007). Temporal trends in the concentration of arsenic, chromium, copper, iron, nickel, vanadium and zinc in mosses across Europe between 1990 and 2000. Atmospheric Environment 41: 6673-6687.

Holy, M., Pesch, R., Schröder, W., Harmens, H., Ilyin, I., et al. (2009). First thorough identification of factors associated with $\mathrm{Cd}, \mathrm{Hg}$ and $\mathrm{Pb}$ concentrations in mosses 
sampled in the European Surveys 1990, 1995, 2000 and 2005. Journal of Atmospheric Chemistry 63: 109-124.

Schröder, W., Holy, M., Pesch, R., Harmens, H., et al. (2010). Are cadmium, lead and mercury concentrations in mosses across Europe primarily determined by atmospheric deposition of these metals? Journal of Soils and Sediments 10: 1572-1584.

By ignoring the above listed references, the review by the Santiago group ignored the discussions that regularly take place within the ICP Vegetation research community (see also point 4), of which the Santiago group are members, to discuss improvements of the moss monitoring manual and the outcome of each moss survey, conducted every five years. Although the Santiago group receive drafts of updated versions of the moss monitoring manual, providing them the opportunity to comment, they have not suggested significant changes to the protocol as discussed in the paper.

The various papers listed above discuss in various level of detail the confounding factors that might affect heavy metal concentrations in moss, such as elevation, moss species, distance to the sea, season of sampling, issues that are subject of the review paper. Hence, it's even more surprising that the paper does not refer to these references, in which the ICP Vegetation community acknowledges the importance of these factors but at the same time showing the disagreement between studies how metal concentrations in mosses are affected by these factors. For example, Harmens et al. (2008) concluded that contrasting results have been found between studies regarding the impact of elevation and season on heavy metal concentrations in mosses. 
9. There are occasions where the current protocol is wrongly quoted in the text and table 1 of the paper, for example:

- Regarding variable 1.1 in table 1, the protocol states 'Similar to previous surveys each country should aim to collect at least 1.5 moss samples/1000 km2. If this is not feasible, a sampling density of at least two moss sample sites per EMEP1 grid $(50 \mathrm{~km} \times 50 \mathrm{~km})$ is recommended.' Hence, the manual does not a priory suggest a choice of two sampling densities.

- Regarding variable 2.2 in table 1, the protocol states 'The sampling points should be located at sites representative of non-urban areas of the respective countries. In remote areas the sampling points should be at least $300 \mathrm{~m}$ from main roads (highways), villages and industries and at least $100 \mathrm{~m}$ away from smaller roads and houses.' Hence, the manual states that sampling should be done in non-urban areas and further details are provided for sampling in remote areas.

Finally, although the proposed improved protocol defines steps more concisely, we doubt that the protocol will be less subjective and easier to fulfil, based on some of the reasons provided above.

\section{References}

Aboal, J.R., Fernández, J.A., Boquete, T., Carballeira, A. (2010). Is it possible to estimate atmospheric deposition of heavy metals by analysis of terrestrial mosses? Science of the Total Environment 408: 6291-6297. 
Harmens, H., Norris, D.A., Koerber, G.R., Buse, A., Steinnes, E., Rühling, Å. (2008). Temporal trends (1990 - 2000) in the concentration of cadmium, lead and mercury in mosses across Europe. Environmental Pollution 151: 368-376.

Harmens, H., Norris, D.A., Sharps, K., Mills, G., Alber, R., Aleksiayenak, Y., Blum, O., Cucu-Man, S.-M., Dam, M., De Temmerman, L., Ene, A., Fernández, J.A., MartinezAbaigar, J., Frontasyeva, M., Godzik, B., Jeran, Z., Lazo, P., Leblond, S., Liiv, S., Magnússon, S.H., Maňkovská, B., Pihl Karlsson, G., Piispanen, J., Poikolainen, J., Santamaria, J.M., Skudnik, M., Spiric, Z., Stafilov, T., Steinnes, E., Stihi, C., Suchara, I., Thöni, L., Todoran, R., Yurukova, L., Zechmeister, H.G. (2015). Heavy metal and nitrogen concentrations in mosses are declining across Europe whilst some "hotspots" remain in 2010. Environmental Pollution 200: 93-104.

Harmens, H., Norris, D.A., Steinnes, E., Kubin, E., Piispanen, J., Alber, R., Aleksiayenak, Y., Blum, O., Coşkun, M., Dam, M., De Temmerman, L., Fernández, J.A., Frolova, M., Frontasyeva, M., González-Miqueo, L., Grodzińska, K., Jeran, Z., Korzekwa, S., Krmar, M., Kvietkus, K., Leblond, S., Liiv, S., Magnússon, S.H., Maňkovská, B., Pesch, R., Rühling, Å., Santamaria, J.M., Schröder, W., Spiric, Z., Suchara, I., Thöni, L., Urumov, V., Yurukova, L., Zechmeister, H.G. (2010). Mosses as biomonitors of atmospheric heavy metal deposition: spatial and temporal trends in Europe. Environmental Pollution 158: 3144-3156.

Holy, M., Pesch, R., Schröder, W., Harmens, H., Ilyin, I., Alber, R., Aleksiayenak, Y., Blum, O., Coşkun, M., Dam, M., De Temmerman, L., Fedorets, N., Figueira, R., Frolova, M., Frontasyeva, M., Goltsova, N., González Miqueo, L., Grodzińska, K., Jeran, Z., Korzekwa, S., Krmar, M., Kubin, E., Kvietkus, K., Larsen, M., Leblond, S., Liiv, S., Magnússon,S., Maňkovská, B., Mocanu, R., Piispanen, J., Rühling, Å., Santamaria, J., Steinnes, E., Suchara, I., Thöni, L., Turcsányi, G., Urumov, V., Wolterbeek, H.T., 
Yurukova, L., Zechmeister, H.G. (2009). First thorough identification of factors associated with $\mathrm{Cd}, \mathrm{Hg}$ and $\mathrm{Pb}$ concentrations in mosses sampled in the European Surveys 1990, 1995, 2000 and 2005. Journal of Atmospheric Chemistry 63: 109-124.

Schröder, W., Holy, M., Pesch, R., Harmens, H., Ilyin, I., Steinnes, E., Alber, R., Aleksiayenak, Y., Blum, O., Coşkun, M., Dam, M., De Temmerman, L., Frolova, M., Frontasyeva, M., González-Miqueo, L., Grodzińska, K., Jeran, Z., Korzekwa, S., Krmar, M., Kubin, E., Kvietkus, K., Leblond, S., Liiv, S., Magnússon,S., Maňkovská, B., Piispanen, J., Rühling, Å., Santamaria, J., Spiric, Z., Suchara, I., Thöni, L., Urumov, V., Yurukova, L., Zechmeister, H.G. (2010). Are cadmium, lead and mercury concentrations in mosses across Europe primarily determined by atmospheric deposition of these metals? Journal of Soils and Sediments 10: 1572-1584.

Skudnik, M., Jeran, Z., Batic, F., Simončič, P., Lojen, S., Kastelec, D. (2014). Influence of canopy drip on the indicative $\mathrm{N}, \mathrm{S}$ and $\mathrm{d}^{15} \mathrm{~N}$ content in moss Hypnum cupressiforme. Environmental Pollution 190: 27-35. 